Article

\title{
Cardiorespiratory Fitness Is Associated with a Reduced Cardiovascular Risk in Occupational Groups with Different Working Conditions: A Cross-Sectional Study among Police Officers and Office Workers
}

\author{
Markus Strauss ${ }^{1,2, *}$, Peter Foshag ${ }^{1}$, Anna Brzęk ${ }^{3}$, Richard Vollenberg ${ }^{4}$, Ulrich Jehn ${ }^{5}$, Henning Littwitz ${ }^{1}$ \\ and Roman Leischik ${ }^{1, *}$
}

Citation: Strauss, M.; Foshag, P.; Brzęk, A.; Vollenberg, R.; Jehn, U.; Littwitz, H.; Leischik, R.

Cardiorespiratory Fitness Is

Associated with a Reduced

Cardiovascular Risk in Occupational

Groups with Different Working

Conditions: A Cross-Sectional Study among Police Officers and Office Workers. J. Clin. Med. 2021, 10, 2025. https://doi.org/10.3390/jcm10092025

Academic Editor: Karol Kaminski

Received: 22 February 2021

Accepted: 3 May 2021

Published: 9 May 2021

Publisher's Note: MDPI stays neutral with regard to jurisdictional claims in published maps and institutional affiliations.

Copyright: (c) 2021 by the authors. Licensee MDPI, Basel, Switzerland. This article is an open access article distributed under the terms and conditions of the Creative Commons Attribution (CC BY) license (https:/ / creativecommons.org/licenses/by/ $4.0 /)$.
1 Department of Cardiology, Faculty of Health, School of Medicine, University Witten/Herdecke, 58095 Hagen, Germany; peter.foshag@uni-wh.de (P.F.); h.littwitz@gmx.de (H.L.)

2 Department of Cardiology I-Coronary and Peripheral Vascular Disease, Heart Failure Medicine, University Hospital Muenster, 48149 Muenster, Germany

3 Department of Physiotherapy, School of Health Sciences, Medical University of Silesia, 40000 Katowice, Poland; aniabrzek@interia.pl

4 Department of Medicine B, Gastroenterology and Hepatology, University Hospital Muenster, 48149 Muenster, Germany; richard.vollenberg@ukmuenster.de

5 Department of Medicine D, Division of General Internal Medicine, Nephrology and Rheumatology, University Hospital of Muenster, 48149 Muenster, Germany; ulrich.jehn@ukmuenster.de

* Correspondence: markus.strauss@ukmuenster.de (M.S.); roman.leischik@uni-wh.de (R.L.)

\begin{abstract}
Several studies reported a high prevalence of cardiovascular risk factors among police officers and office workers, and adequate cardiorespiratory fitness was reported to have protective effects in reducing cardiovascular risk. Therefore, the present study aimed to evaluate the effects of cardiorespiratory fitness on reducing cardiovascular risk factors in these occupational groups. This cross-sectional study enrolled 101 male participants (55 police officers and 46 office workers). Cardiorespiratory fitness was assessed via spiroergometry. Cardiovascular risk factors were also examined, and the 10-year cardiovascular risk and heart/vascular age were reported using the Framingham risk score. In both groups, higher cardiorespiratory fitness was associated with lower cardiovascular risk factors. Police officers and office workers with higher cardiorespiratory fitness demonstrated significantly lower values in BMI, waist circumference, body fat percentage, diastolic resting blood pressure, heart rate, triglycerides and total cholesterol values, and 10-year cardiovascular risk and heart/vascular age (all factors $p<0.0077$, age adjusted). Police officers and office workers mostly presented low levels of cardiorespiratory fitness: $60 \%$ of police officers and $58 \%$ of office workers were considered "not fit and obese". Despite different working conditions, both occupational groups had a high rate of low cardiorespiratory fitness levels and showed no differences in their cardiovascular risk profiles. In both groups, cardiorespiratory fitness reduced cardiovascular risk factors, but there was no difference in the influence of cardiorespiratory fitness on cardiovascular risk factors.
\end{abstract}

Keywords: police officer; office worker; cardiovascular prevention; cardiorespiratory fitness; risk profile; cardiovascular risk factors; cardiovascular risk

\section{Introduction}

One of the most important factors for protection against cardiovascular diseases is physical activity [1,2]. Previous studies showed that professional work with high physical activity protects against cardiovascular disease [3]. On the other hand, Coenen et al. [4] demonstrated that men with a high level of occupational physical activity had an $18 \%$ increased risk of early mortality compared to those engaged in low levels of occupational 
physical activity. Overall, there are great differences in physical activity levels between different professions. Today, physical activity and health plasticity are additionally dependent on environmental circumstances [5]. Moreover, possible pandemics (e.g., COVID-19), rapid globalization, urbanization, an aging society, and an increase in chronic diseases pose new and complex challenges to all health care systems [6,7]. A sedentary work profession may lead to higher mortality if the worker's lifestyle behaviors during leisure time influence mortality in a negative manner. This issue is multifaceted and is also strongly affected by income. The German police officers in our study had a moderate-income, generally sedentary work characteristics, and low counter-regulation.

The working conditions of office worker are characterized by predominantly sedentary work [8]. A meta-analysis by van Uffelen et al. [9] showed negative associations between sitting time at work and increased cardiometabolic biomarkers and risk. Studies from different countries have frequently reported unhealthy lifestyles and physical inactivity among office workers [10]. In contrast to office workers, working as a police officer is known to be dangerous. Thus, to ensure that the police officer remains safe, good physical fitness is mandatory. Police officers' working conditions, however, are inhomogeneous and differ depending on the officer's main work activity. Some police officers mainly carry out sedentary office activities, whereas others primarily engage in physically demanding work during their everyday patrol services. Past studies have indicated a high prevalence of risk factors for cardiovascular disease among police officers [11]. Exposure to physical stress among police officers was associated with obesity, dyslipidemia, and hypertension as well as impaired glucose metabolism [12]. However, physical fitness among police officers has not yet been systematically reviewed in the literature. A current systematic review of police officers' physical fitness levels provided values similar to or above the average among the general population [13]. On the other hand, subsequent studies provide growing evidence that the physical fitness of police officers is below the recommended standards for general health [14].

Police officers require good fitness for emergency situations, as do all who work in the area of public safety (e.g., firefighters and medical staff) $[15,16]$. Adequate physical fitness is especially necessary on active patrol duty. Izawa et al. [17] noted that even police officers in the administrative service must always expect to be deployed on patrol duty.

The physical demands of on-duty policemen can be high at any given time. For example, a police officer may be at rest but then suddenly have to intervene in an emergency situation. However, accelerometer measurements suggest that male police officers engage in less job-related physical activity than secretaries and appear to be more active on their off-duty days than during their work hours [18]. However, if physical activity is not pursued during off-duty periods, police officers tend to become obese. Additionally, there is a correlation between activity levels and areas of police duty, which can require different demands. In general, police officers who are more stressed tend to be less active [18,19].

Under this background, the present study investigates whether higher cardiorespiratory fitness (CRF) is associated with cardiovascular risk factor (CVRF)reductions for police officers and office workers, who represent two groups with different working conditions.

\section{Materials and Methods}

\subsection{Study Population}

This cross-sectional study included 101 male participants (55 police officers and 46 office workers) from North-Rhine-Westphalia, Germany. The inclusion criterion for police officers was employment in shift-based police-patrol work with the federal police force. Office workers were employed in administrative offices involving predominantly sedentary tasks. These workers were employed in tax offices or municipal administration and performed desk work. Desk work was characterized as sedentary work in a full-time job ( $>35 \mathrm{~h}$ per week) in accordance with the criteria of the Sedentary Behavior Research Network (SBRN) [20]. Examinations were performed at the Center of Sports Medicine in Hagen by a trained clinical physician. 
The ethical review board of the University Witten/Herdecke approved the study, which was performed in accordance with the ethical principles in the Deceleration of Helsinki. Written informed consent was obtained from all participants.

\subsection{Assessment of Cardiovascular Risk Factors (CVRF)}

On day one of the examination, the anthropometric characteristics, participant histories, resting heart rate and blood pressure measurements, and blood samples were obtained.

Using a questionnaire, each individual's nicotine consumption (cig./day) and years of professional experience were determined. Body weight, body fat (\%), and body composition were measured using a Tanita BC-418MA Segmental Body Composition Analyzer (Tanita Corporation, Tokyo, Japan). The measurement of height in a standing position was performed using a clinic stadiometer. Body mass index (BMI) was calculated as the weight in kilograms divided by the square of height in meters. In a standing position, waist circumference was measured at the center of the lower edge of the ribs and the iliac crest's upper edge.

Diastolic (RDBP) and systolic (RSBP) resting blood pressure and heart rate (HR) were measured after a five-minute break in the supine position. In this position, blood pressure was measured three times at intervals of one minute. The mean value of these three bloodpressure measurements was taken as the resting blood pressure. HR measurements were performed using a 12-lead ECG.

To ensure valid blood collection, participants were asked to fast (no eating and drinking for $6 \mathrm{~h}$ prior to examination). Venous blood collection included the following parameters: total cholesterol, high-density lipoprotein (HDL), low-density lipoprotein (LDL), and triglycerides.

Calculation of the cardiovascular risk profile and heart/vascular age was based on the Framingham score [21]. This study used the 10-year cardiovascular risk score calculator and heart/vascular age calculator [22]. The following parameters were considered in the calculations: age, the presence of diabetes mellitus, smoking, the presence of treated or untreated systolic blood pressure, total cholesterol, HDL levels, and BMI. The 10-year cardiovascular risk was divided into three risk groups: $<10 \%$ low risk, $10-20 \%$ moderate risk, and $>20 \%$ high risk.

\subsection{Assessment of Cardiorespiratory Fitness (CRF)}

Exercise spiroergometry testing with an electrocardiogram and estimation of oxygen consumption (VO2max/METs) was performed to assess cardiorespiratory fitness [23]. Spiroergometry exercise testing was performed using a ramp protocol starting at 50 watts and increasing the power by 25 watts every $2 \mathrm{~min}$. Criteria for the end of the test were a subjectively exhausted participant with no further increase in maximal oxygen uptake for $20 \mathrm{~s}$, achieving $85 \%$ of the individual maximum predicted heart rate (defined as 220 -age), and/or the proband being unable maintain a cycle pace of 80 rotations per minute. The metabolic equivalent (MET) values achieved during spiroergometry were measured and analyzed. One MET was considered $3.5 \mathrm{~mL} \cdot \mathrm{kg}^{-1} \cdot \mathrm{min}^{-1}$, which is often characterized as the metabolic cost of resting quietly [24].

The participants were divided into four groups based on their achieved METs to describe their cardiorespiratory fitness. The four groups were as follows: very low ( $\leq 10 \mathrm{METs})$, low (10 to $12 \mathrm{METs}$ ), intermediate (>12 to $14 \mathrm{METs})$, and high fitness levels ( $>14$ METs).

\subsection{Statistical Analysis}

Stata/IC 13.1 for Windows (StataCorp LP, College Station, TX, USA) was used for the statistical analysis. The baseline characteristics here are described using the mean, standard deviation (SD), and median. For the categorical variables, frequency is reported. Quantitative variables are presented based on an analysis of variance, and the $x^{2}$ test was used for a group comparison of the categorical variables. To describe the influence of MET 
and both MET and BMI on CVD risk factors, linear regression models were determined. These descriptions were produced using different models (unadjusted, adjusted for age, adjusted for age, and BMI). The statistical tests were two-sided with a significance level of 0.05 .

\section{Results}

\subsection{Baseline Characteristics}

The baseline characteristics of the participants are summarized in Table 1.

Table 1. Baseline characteristics of the participants.

\begin{tabular}{ccccc}
\hline \multicolumn{2}{c}{ Police Officer $(\boldsymbol{n}=\mathbf{5 5})$} & & \multicolumn{2}{c}{ Office Worker $(\boldsymbol{n}=\mathbf{4 6})$} \\
\hline Variables & Mean \pm SD & Min-Max & Mean \pm SD & Min-Max \\
\hline Age & $45.3 \pm 7.8$ & $25-58$ & $45.8 \pm 10.0$ & $26-62$ \\
BMI $\left(\mathrm{kg} / \mathrm{m}^{2}\right)$ & $28.0 \pm 3.2$ & $21.9-34.5$ & $26.4 \pm 4.1$ & $21.1-43.0$ \\
Body fat (\%) & $2.5 \pm 6.0$ & $0.0-20.0$ & $1.7 \pm 5.5$ & $0.0-25.0$ \\
Tobacco use (Cigarettes/day) & $21.4 \pm 5.6$ & $8.2-34.8$ & $20.8 \pm 6.5$ & $9.0-37.0$ \\
Waist circumference (cm) & $97.8 \pm 12.4$ & $68-127$ & $97.3 \pm 11.7$ & $80-132$ \\
Professional experience (years) & $25.2 \pm 8.4$ & $5.0-41.0$ & $21.1 \pm 10.8$ & $3.0-46.0$ \\
10-year cardiovascular risk & $9.6 \pm 7.4$ & $1.2-30.0$ & $9.7 \pm 9.2$ & $1.0-51.3$ \\
(Framingham) & $51.1 \pm 13.9$ & $27-85$ & $49.6 \pm 15.5$ & $26-86$ \\
Heart/vascular age & $9.7 \pm 2.3$ & $5.3-14.5$ & $9.6 \pm 2.3$ & $5.4-13.8$ \\
METs absolute & $2.24 \pm 0.73$ & $0.82-4.65$ & $2.04 \pm 0.65$ & $0.92-4.12$ \\
Abs. VO2max (L/min.) & $34.1 \pm 8.0$ & $19.0-51.0$ & $34.1 \pm 8.1$ & $19.0-49.0$ \\
Rel. VO2max (mL/kg/KG) & & & &
\end{tabular}

The examined police officers had an average age of $45.3 \pm 7.8$ years, whereas the office workers were, on average, $45.8 \pm 10.0$ years old. Based on the international BMI classification, $61.8 \%$ of the police officers and $43.5 \%$ of the office workers were overweight and $23.6 \%$ of the police officers and $13.0 \%$ of office workers were obese. Normal weight was measured for $14.5 \%$ of police officers and $43.5 \%$ of office workers. The average waist circumference of the police officers was $97.8 \pm 12.4 \mathrm{~cm}$, and that of office workers was $97.3 \pm 11.7 \mathrm{~cm}$. The average values of both groups were above the reference value of $84 \mathrm{~cm}$ according to the International Diabetes Foundation. The MET score was used for measuring CRF in both groups. Police officers and office workers achieved the same average METs of $9.7 \pm 2.3$. In most cases, both groups achieved METs $\leq 10$ (police officers: $54.5 \%$; office workers: $58.7 \%$ ). METs scores of $>10$ to $\leq 12$ were obtained by $23.9 \%$ of police officers and $27.3 \%$ of office workers, and METs scores of 12 to $\leq 14$ were achieved by $17.4 \%$ of police officers and $16.4 \%$ of office workers. Only one police officer $(1.8 \%)$ and no office workers achieved METs $>14$. Police officers presented an average 10-year cardiovascular risk of $9.6 \pm 7.4 \%$ and a heart/vascular age of $51.1 \pm 13.9$ years. The 10-year cardiovascular risk of office workers $(9.7 \pm 9.2 \%)$ was nearly the same as that of police officers, but the average heart/vascular age of office workers was lower than that of police officers (49.6 \pm 15.5 years).

\subsection{Association between Cardiovascular Risk Factors and Cardiorespiratory Fitness}

Table 2 summarizes the associations of CVRF and CRF among the police officers and office workers. These results are presented using three different analytical models: unadjusted, adjusted for age, and adjusted for both age and BMI. Only one police officer and no office workers were included in the METs $>14$ group. Consequently, no valid observations could be derived, and the METs $>14$ group is not reported in Table 2 . The unadjusted analysis indicates significant associations between higher CRF and lower BMI, lower waist circumference, lower body fat, lower HR, lower triglycerides (only police officers), lower total cholesterol, lower HDL-cholesterol, lower LDL-cholesterol, lower professional experience (only police officers), and lower 10-year cardiovascular risk and heart/vascular age in both groups (police officers and office workers) (all factors $p<0.0483$ ). 
Table 2. Cardiovascular risk factors of each MET category among police officers and office workers.

\begin{tabular}{|c|c|c|c|c|c|c|}
\hline & METs $\leq 10$ & $10<$ METs $\leq 12$ & $12<$ METs $\leq 14$ & & & \\
\hline & Police Officer $n=30$, & Police Officer $n=15$, & Police Officer $n=9$, & p1 & p2 & p3 \\
\hline & Office Worker $n=27$ & Office Worker $n=11$ & Office Worker $n=8$ & & & \\
\hline \multicolumn{7}{|l|}{ Age } \\
\hline Police officer & $48.6(6.2)$ & $44.3(6.6)$ & $36.9(8.5)$ & 0.0006 & $\mathrm{n} / \mathrm{a}$ & $\mathrm{n} / \mathrm{a}$ \\
\hline Office worker & $47.4(9.4)$ & $42.9(10.6)$ & 44.6 (11.7) & 0.4463 & $\mathrm{n} / \mathrm{a}$ & $\mathrm{n} / \mathrm{a}$ \\
\hline \multicolumn{7}{|l|}{ BMI, $\mathrm{kg} / \mathrm{m}^{2}$} \\
\hline Police officer & $29.5(3.2)$ & $26.4(2.4)$ & $25.7(1.5)$ & $<0.0001$ & $<0.0001$ & $\mathrm{n} / \mathrm{a}$ \\
\hline Office worker & $27.9(4.6)$ & $24.3(1.7)$ & $24.3(2.1)$ & 0.0031 & 0.0032 & $\mathrm{n} / \mathrm{a}$ \\
\hline \multicolumn{7}{|l|}{$\begin{array}{l}\text { Waist circumference, } \\
\mathrm{cm}\end{array}$} \\
\hline Police officer & $104.3(11.3)$ & $91.2(10.4)$ & $87.5(3.9)$ & $<0.0001$ & 0.0002 & 0.4296 \\
\hline Office worker & $102.5(11.6)$ & $90.9(6.5)$ & $88.4(7.6)$ & 0.0002 & 0.0003 & 0.0355 \\
\hline \multicolumn{7}{|l|}{ Body fat, $\%$} \\
\hline Police officer & $24.5(4.2)$ & $19.7(4.3)$ & $14.1(3.8)$ & $<0.0001$ & $<0.0001$ & 0.0020 \\
\hline Office worker & $24.0(6.1)$ & $16.2(2.1)$ & $16.1(5.5)$ & $<0.0001$ & $<0.0001$ & 0.0031 \\
\hline \multicolumn{7}{|l|}{$\mathrm{RSBP}, \mathrm{mmHg}$} \\
\hline Police officer & $129.3(13.2)$ & $126.0(13.5)$ & $123.9(4.9)$ & 0.1882 & 0.5133 & 0.8890 \\
\hline Office worker & $130.0(11.8)$ & $129.1(13.0)$ & $126.2(10.6)$ & 0.6849 & 0.6895 & 0.4835 \\
\hline \multicolumn{7}{|l|}{$\mathrm{RDBP}, \mathrm{mmHg}$} \\
\hline Police officer & $88.1(11.7)$ & $82.7(8.8)$ & $82.2(4.4)$ & 0.0748 & 0.0046 & 0.1055 \\
\hline Office worker & $87.6(8.5)$ & $85.5(9.3)$ & $85.0(9.3)$ & 0.6795 & 0.7648 & 0.9294 \\
\hline \multicolumn{7}{|l|}{$\mathrm{HR}, \mathrm{bpm}$} \\
\hline Police officer & $73.4(11.6)$ & $65.0(6.8)$ & $60.2(10.9)$ & 0.0022 & 0.0007 & 0.0116 \\
\hline Office worker & $74.1(13.7)$ & $65.4(6.8)$ & $62.8(8.6)$ & 0.0118 & 0.0115 & 0.0581 \\
\hline \multicolumn{7}{|l|}{ Triglycerides, mg/dL } \\
\hline Police officer & $251.7(166.8)$ & $108.1(42.9)$ & $103.1(43.8)$ & 0.0002 & 0.0003 & 0.0655 \\
\hline Office worker & $175.0(90.7)$ & $165.7(103.1)$ & $113.4(67.5)$ & 0.1101 & 0.1845 & 0.2274 \\
\hline \multicolumn{7}{|l|}{$\begin{array}{l}\text { Total cholesterol, } \\
\mathrm{mg} / \mathrm{dL}\end{array}$} \\
\hline Police officer & $220.9(42.5)$ & $194.5(34.6)$ & $175.8(16.2)$ & 0.0001 & 0.0077 & 0.0717 \\
\hline Office worker & $213.4(30.9)$ & $203.5(30.9)$ & $188.0(16.4)$ & 0.0127 & 0.0087 & 0.0048 \\
\hline \multicolumn{7}{|l|}{$\begin{array}{l}\text { HDL-cholesterol, } \\
\mathrm{mg} / \mathrm{dL}\end{array}$} \\
\hline Police officer & $43.2(11.9)$ & $55.7(15.5)$ & $54.8(11.8)$ & 0.0052 & 0.0585 & 0.3814 \\
\hline Office worker & $52.7(12.2)$ & $55.6(18.7)$ & $66.6(14.0)$ & 0.0431 & 0.0314 & 0.0715 \\
\hline \multicolumn{7}{|l|}{$\begin{array}{l}\text { LDL-cholesterol, } \\
\mathrm{mg} / \mathrm{dL}\end{array}$} \\
\hline Police officer & $142.1(40.1)$ & $120.5(30.2)$ & $103.8(23.7)$ & 0.0030 & 0.0844 & 0.3910 \\
\hline Office worker & $125.7(22.6)$ & $114.9(24.5)$ & $100.0(14.4)$ & 0.0016 & 0.0033 & 0.0018 \\
\hline \multicolumn{7}{|l|}{$\begin{array}{l}\text { Professional } \\
\text { experience, years }\end{array}$} \\
\hline Police officer & $28.9(6.4)$ & $23.7(8.0)$ & $15.6(7.6)$ & $<0.0001$ & 0.1472 & 0.2099 \\
\hline Office worker & $20.7(11.0)$ & $21.0(9.2)$ & $22.6(13.4)$ & 0.9317 & 0.1771 & 0.5781 \\
\hline \multicolumn{7}{|l|}{$\begin{array}{l}\text { 10-year } \\
\text { cardiovascular risk } \\
\text { (Framingham) }\end{array}$} \\
\hline Police officer & $13.2(8.0)$ & $6.2(3.6)$ & $4.2(3.0)$ & $<0.0001$ & 0.0031 & 0.0956 \\
\hline Office worker & $11.8(10.4)$ & $7.7(7.1)$ & $5.3(4.4)$ & 0.0445 & 0.0128 & 0.0405 \\
\hline \multicolumn{7}{|l|}{ Heart/vascular age } \\
\hline Police officer & $58.3(12.8)$ & $45.3(8.3)$ & $38.6(10.6)$ & $<0.0001$ & 0.0039 & 0.1750 \\
\hline Office worker & $53.7(15.2)$ & $45.6(16.0)$ & $41.2(12.1)$ & 0.0483 & 0.0003 & 0.0023 \\
\hline
\end{tabular}


When adjusted for age, significantly higher values of BMI, waist circumference, body fat percentage, RDBP, HR, triglycerides, total cholesterol, 10-year cardiovascular risk, and heart/vascular age were found to be inversely related to lower CRF levels (all factors $p<0.0077)$. After adjusting for age and BMI, an inverse relationship between CRF and CVRF in police officers was obtained for HR and body fat (both factors $p<0.0116$ ). In office workers, higher CRFs were significantly related to lower BMI, lower waist circumference, higher body fat, lower HR, lower triglycerides, lower LDL-cholesterol, and lower 10-year cardiovascular risk and heart/vascular age after adjusting the values for age (all factors $p<0.0314)$. Overall, a significantly lower waist circumference, lower body fat, lower total cholesterol, lower LDL-cholesterol, and lower 10-year cardiovascular risk and heart/vascular age were detected in office workers with higher CRF after adjusting for age and BMI (all factors $p<0.0405$ ).

Based on the CRF and BMI, the participants of both groups (police officers and office workers) were divided into four level groups: low fitness (METs $\leq 12$ ) and not obese $(\mathrm{BMI}<30)$, fit (METs $>12)$ and not obese $(\mathrm{BMI}<30)$, low fitness (METs $\leq 12)$ and obese $(B M I \geq 30)$, and fit (METs $>12)$ and obese (BMI $\geq 30$ ). Only one police officer and two office workers were assigned to the group "fit and obese". Consequently, no valid observations could be derived. Therefore, the group "fit and obese" was not considered in the corresponding Table 3, which presents the results of the four level groups and CVRF. We observed a large variance in the association between fitness level and body composition and CVRF in the groups of police officers and office workers.

Table 3. Participants (police officers and office workers) divided by METs and BMI in four different level groups (mean and SD).

\begin{tabular}{|c|c|c|c|c|c|c|}
\hline & $\begin{array}{c}\text { Low Fitness } \\
\text { and Obese }\end{array}$ & $\begin{array}{c}\text { Low Fitness and } \\
\text { Not Obese }\end{array}$ & Fit and Not Obese & \multirow{3}{*}{ p1 } & \multirow{3}{*}{$\mathrm{p} 2$} & \multirow{3}{*}{ p3 } \\
\hline & Police Officer $n=33$, & Police Officer $n=12$, & Police Officer $n=9$, & & & \\
\hline & Office Worker $n=25$ & Office Worker $n=13$ & Office Worker $n=6$ & & & \\
\hline \multicolumn{7}{|l|}{ Age } \\
\hline Police officer & $48.4(5.9)$ & $44.0(7.4)$ & $36.7(8.4)$ & 0.0005 & $\mathrm{n} / \mathrm{a}$ & $\mathrm{n} / \mathrm{a}$ \\
\hline Office worker & $47.9(7.0)$ & $42.6(13.4)$ & $44.3(10.4)$ & 0.3374 & $\mathrm{n} / \mathrm{a}$ & $\mathrm{n} / \mathrm{a}$ \\
\hline \multicolumn{7}{|l|}{$\mathrm{BMI}, \mathrm{kg} / \mathrm{m}^{2}$} \\
\hline Police officer & $29.7(2.8)$ & $25.1(1.7)$ & $25.4(1.3)$ & - & - & \\
\hline Office worker & $28.6(4.4)$ & $23.6(1.1)$ & $23.5(1.7)$ & - & - & \\
\hline \multicolumn{7}{|l|}{$\begin{array}{l}\text { Waist circumference, } \\
\mathrm{cm}\end{array}$} \\
\hline Police officer & $105.3(9.5)$ & $85.1(6.4)$ & $87.2(3.3)$ & - & - & - \\
\hline Office worker & $105.1(9.8)$ & $87.8(2.8)$ & $85.2(5.1)$ & - & - & - \\
\hline \multicolumn{7}{|l|}{ Body fat, $\%$} \\
\hline Police officer & $24.7(3.8)$ & $18.2(3.9)$ & $15.3(3.8)$ & $<0.0001$ & $<0.0001$ & 0.0196 \\
\hline Office worker & $24.3(6.1)$ & $16.8(2.6)$ & $14.3(5.0)$ & $<0.0001$ & $<0.0001$ & 0.0679 \\
\hline \multicolumn{7}{|l|}{$\mathrm{RSBP}, \mathrm{mmHg}$} \\
\hline Police officer & $129.3(12.8)$ & $125.0(14.5)$ & $126.1(7.0)$ & 0.5021 & 0.6277 & 0.9738 \\
\hline Office worker & $131.6(12.8)$ & $126.2(9.6)$ & $126.7(12.1)$ & 0.3185 & 0.2870 & 0.6495 \\
\hline \multicolumn{7}{|l|}{ RDBP, mmHg } \\
\hline Police officer & $87.7(11.8)$ & $82.5(7.5)$ & $83.3(5.0)$ & 0.1699 & 0.0228 & 0.5933 \\
\hline Office worker & $89.0(9.1)$ & $83.1(6.3)$ & $86.7(10.3)$ & 0.0769 & 0.1205 & 0.7017 \\
\hline \multicolumn{7}{|l|}{$\mathrm{HR}, \mathrm{bpm}$} \\
\hline Police officer & $73.1(11.4)$ & $63.9(6.2)$ & $62.0(11.4)$ & 0.0020 & 0.0010 & 0.0323 \\
\hline Office worker & $73.8(12.8)$ & $67.5(11.9)$ & $62.3(10.1)$ & 0.0495 & 0.0326 & 0.1727 \\
\hline
\end{tabular}


Table 3. Cont.

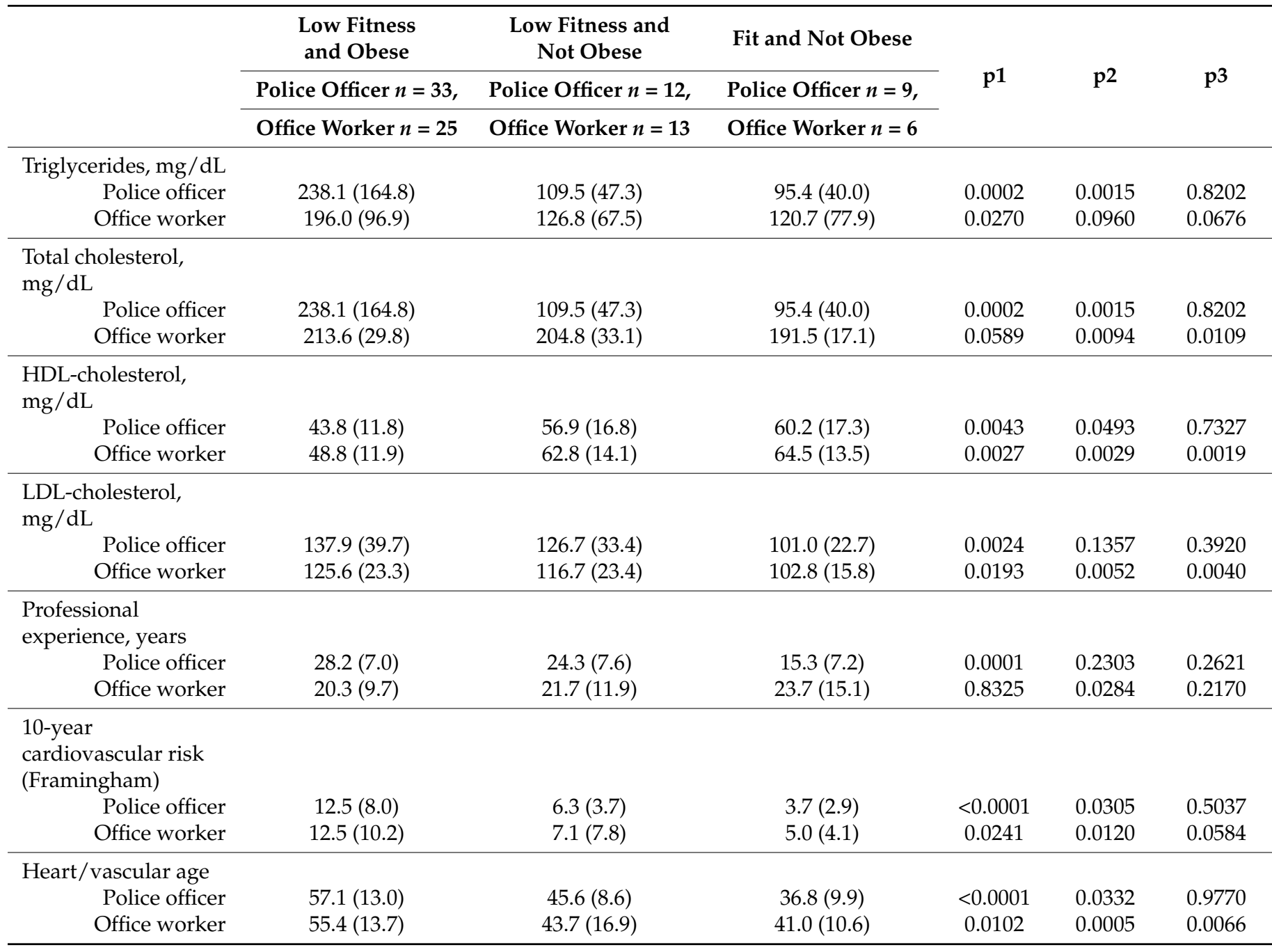

p1: unadjusted; p2: adjusted for age; p3: adjusted for age and BMI.

In most cases, the police officers and office workers belonged to the "low fit and obese" group (police officers $n=33$; office workers $n=25$ ). "Low fitness and not obese" was the second largest group for both police officers $(n=12)$ and office workers $(n=13)$, followed by "fit and not obese" (police officers $n=9$; office workers $n=6$ ). A comparison of the four groups among police officers and office workers showed significant differences in the unadjusted model only for professional experience (police officers) and triglycerides (office workers) and only for RDBP (police officers) and professional experience (office workers) in the age-adjusted model. After adjusting for age and BMI, there was a significant difference for office workers only in total cholesterol. Participants showed significantly different parameters between the groups in body fat percentage, HR, triglycerides, total cholesterol, HDL-cholesterol, 10-year cardiovascular risk, and heart/vascular age (all of these parameters differed only for police officers) after consideration of the models with and without adjustment for age. Statistically significant differences in all three models were detected for the parameters of body fat percentage (police officers and office workers), HDL-cholesterol, and heart/vascular age (these parameters differed only in office workers). In all statistical tests, the parameters of RDBP for office workers and RSBP for both police officers and office workers were not different between the groups.

A linear regression model was developed to show the relationship between CVRF and CRF (MET) as continuous variables. These relationships for the group of police officers are presented in Table 4, while those for office workers are presented in Table 5. 
Table 4. Linear regression models of cardiovascular risk factors and METs as continuous variable for police officers.

\begin{tabular}{|c|c|c|c|c|c|c|}
\hline \multirow{2}{*}{ Police Officers } & \multicolumn{2}{|c|}{ Model 1} & \multicolumn{2}{|c|}{ Model 2} & \multicolumn{2}{|c|}{ Model 3} \\
\hline & Beta (SE) & $p$ & Beta (SE) & $p$ & Beta (SE) & $p$ \\
\hline Age & $-1.81(0.35)$ & $<0.0001$ & $\mathrm{n} / \mathrm{a}$ & $\mathrm{n} / \mathrm{a}$ & $\mathrm{n} / \mathrm{a}$ & $\mathrm{n} / \mathrm{a}$ \\
\hline BMI, $\mathrm{kg} / \mathrm{m}^{2}$ & $-0.84(0.15)$ & $<0.0001$ & $-0.94(0.17)$ & $<0.0001$ & $\mathrm{n} / \mathrm{a}$ & $\mathrm{n} / \mathrm{a}$ \\
\hline Waist circumference, $\mathrm{cm}$ & $-3.53(0.61)$ & $<0.0001$ & $-3.38(0.69)$ & $<0.0001$ & $-0.82(0.46)$ & 0.0797 \\
\hline Body fat, $\%$ & $-1.74(0.28)$ & $<0.0001$ & $-1.75(0.31)$ & $<0.0001$ & $-0.92(0.32)$ & 0.0057 \\
\hline RSBP, mmHg & $-0.67(0.76)$ & 0.3823 & $-0.69(0.99)$ & 0.4868 & $0.16(1.07)$ & 0.8846 \\
\hline $\mathrm{RDBP}, \mathrm{mmHg}$ & $-0.67(0.65)$ & 0.3089 & $-1.26(0.71)$ & 0.0792 & $-0.14(0.89)$ & 0.8756 \\
\hline $\mathrm{HR}, \mathrm{bpm}$ & $-2.68(0.60)$ & $<0.0001$ & $-3.16(0.66)$ & $<0.0001$ & $-3.33(0.84)$ & 0.0002 \\
\hline Triglycerides, mg/dL & $-30.88(8.95)$ & 0.0011 & $-25.16(8.59)$ & 0.0050 & $-4.92(6.94)$ & 0.4816 \\
\hline Total cholesterol, mg/dL & $-6.03(2.05)$ & 0.0047 & $-4.54(2.43)$ & 0.0673 & $-2.82(2.85)$ & 0.3269 \\
\hline HDL-cholesterol, mg/dL & $3.24(0.92)$ & 0.0009 & $2.70(1.06)$ & 0.0135 & $1.36(1.14)$ & 0.2388 \\
\hline LDL-cholesterol, mg/dL & $-5.36(2.23)$ & 0.0199 & $-3.15(2.35)$ & 0.1856 & $-0.93(2.92)$ & 0.7517 \\
\hline Professional experience, years & $-1.95(0.39)$ & $<0.0001$ & $-0.41(0.30)$ & 0.1700 & $-0.52(0.41)$ & 0.2121 \\
\hline $\begin{array}{l}\text { 10-year cardiovascular risk } \\
\text { (Framingham) }\end{array}$ & $-2.15(0.39)$ & $<0.0001$ & $-1.30(0.33)$ & 0.0002 & $-1.10(0.45)$ & 0.0193 \\
\hline Heart/vascular age & $-4.15(0.66)$ & $<0.0001$ & $-2.22(0.54)$ & 0.0002 & $-1.65(0.70)$ & 0.0218 \\
\hline
\end{tabular}

Model 1: linear regression, unadjusted; Model 2: linear regression, adjusted for age; Model 3: linear regression, adjusted for age and BMI.

Table 5. Linear regression models of cardiovascular risk factors and METs as continuous variables for office workers.

\begin{tabular}{|c|c|c|c|c|c|c|}
\hline \multirow{2}{*}{ Office Workers } & \multicolumn{2}{|c|}{ Model 1} & \multicolumn{2}{|c|}{ Model 2} & \multicolumn{2}{|c|}{ Model 3} \\
\hline & Beta (SE) & $p$ & Beta (SE) & $p$ & Beta (SE) & $p$ \\
\hline Age & $-1.07(0.60)$ & 0.0797 & $\mathrm{n} / \mathrm{a}$ & $\mathrm{n} / \mathrm{a}$ & $\mathrm{n} / \mathrm{a}$ & $\mathrm{n} / \mathrm{a}$ \\
\hline BMI, $\mathrm{kg} / \mathrm{m}^{2}$ & $-1.03(0.28)$ & 0.0008 & $-1.02(0.28)$ & 0.0006 & $\mathrm{n} / \mathrm{a}$ & $\mathrm{n} / \mathrm{a}$ \\
\hline Waist circumference, $\mathrm{cm}$ & $-3.55(0.60)$ & $<0.0001$ & $-3.38(0.58)$ & $<0.0001$ & $-1.26(0.35)$ & 0.0009 \\
\hline Body fat, $\%$ & $-1.81(0.35)$ & $<0.0001$ & $-1.87(0.35)$ & $<0.0001$ & $-0.88(0.29)$ & 0.0039 \\
\hline RSBP, mmHg & $-0.64(0.93)$ & 0.4932 & $-0.61(0.90)$ & 0.5001 & $1.46(0.71)$ & 0.0451 \\
\hline $\mathrm{RDBP}, \mathrm{mmHg}$ & $-0.53(0.57)$ & 0.3533 & $-0.43(0.60)$ & 0.4722 & $0.57(0.66)$ & 0.3879 \\
\hline $\mathrm{HR}, \mathrm{bpm}$ & $-1.79(0.80)$ & 0.0299 & $-1.91(0.88)$ & 0.0363 & $-1.62(0.93)$ & 0.0910 \\
\hline Triglycerides, mg/dL & $-10.46(4.86)$ & 0.0370 & $-7.58(5.08)$ & 0.1428 & $-9.38(6.40)$ & 0.1500 \\
\hline Total cholesterol, mg/dL & $-3.91(1.65)$ & 0.0221 & $-2.19(1.43)$ & 0.1328 & $-3.91(1.71)$ & 0.0276 \\
\hline HDL-cholesterol, mg/dL & $2.39(0.83)$ & 0.0063 & $2.66(0.86)$ & 0.0035 & $3.00(1.06)$ & 0.0068 \\
\hline LDL-cholesterol, mg/dL & $-4.08(1.18)$ & 0.0012 & $-3.16(1.13)$ & 0.0075 & $-4.79(1.42)$ & 0.0016 \\
\hline Professional experience, years & $0.12(0.67)$ & 0.8623 & $0.96(0.51)$ & 0.0687 & $0.62(0.69)$ & 0.3726 \\
\hline $\begin{array}{l}\text { 10-year cardiovascular risk } \\
\text { (Framingham) }\end{array}$ & $-1.45(0.69)$ & 0.0400 & $-0.90(0.58)$ & 0.1260 & $-0.92(0.80)$ & 0.2514 \\
\hline Heart/vascular age & $-2.66(0.93)$ & 0.0067 & $-1.36(0.60)$ & 0.0273 & $-1.20(0.74)$ & 0.1115 \\
\hline
\end{tabular}

Model 1: linear regression, unadjusted; Model 2: linear regression, adjusted for age; Model 3: linear regression, adjusted for age and BMI.

Among police officers, significantly different relationships were observed between lower CVRF and CRF in the unadjusted model $(p<0.0199)$. Only the relationships between $\operatorname{RSBP}(p=0.3823)$ and RDBP $(p=0.3089)$, and CRF in the unadjusted model were not significantly different. When adjusted for age, linear regression was not significantly different for the parameters of RSBP, RDBP, total cholesterol, LDL-cholesterol, and professional experience $(p>0.05)$. The other parameters showed a significant relationship between cardiovascular risk parameters and CRF $(p<0.0135)$. Linear regression after adjustments for age and BMI presented a significant relationship for the following parameters: body fat percentage, HR, 10-year cardiovascular risk, and heart/vascular age (all parameters $p<0.0218$ ).

In the unadjusted model, office workers showed that every increase in METs was associated with a significant decrease in examined CVRF, except for RSBP, RDBP, and professional experience. A significant difference after adjustment for age was presented for CVRF BMI, waist circumference, body fat percentage, HR, HDL-cholesterol, LDLcholesterol, and heart/vascular age (all parameters $p<0.0363$ ). After adjustment for age and BMI, significant differences were detected for waist circumference, body fat percentage, 
RSBP, total cholesterol, HDL-cholesterol, and LDL-cholesterol in office workers (all parameters $p<0.0451$ ), except for total cholesterol, LDL-cholesterol, and work experience. When adjusted for age and BMI, the values were only significantly lower for body fat percentage $(p=0.0061)$. The effects of fitness levels on waist circumference and body fat percentage were highly significant in the unadjusted and adjusted analysis for age $(p<0.0001)$. In contrast, the effect was harmonized after an additional adjustment for BMI.

\section{Discussion}

The present study aimed to examine the influence of CRF on CVRF in different professions. We found that higher CRF is correlated with lower cholesterol levels and lower abdominal adiposity. One very important finding is that the 10-year cardiovascular risk (Framingham score) was lower in both groups. This shows that not only one's profession but also one's CRF is an important indicator for cardiovascular risk. Police officers and office workers who engage in sedentary work can improve their situation by training the cardiovascular system, e.g., in their leisure time.

Previous studies reported higher cardiovascular risk parameters among police officers and office workers with lower CRF $[19,25]$. The present study indicates that CRF has beneficial effects on CVRF for police officers and office workers. The study results showed that higher CRF levels in police officers and office workers (expressed as higher METs values) were significantly associated with lower values for BMI, waist circumference, body fat percentage, HR, total cholesterol, and 10-year cardiovascular risk as well as heart/vascular age (according to Framingham) after adjusting for age. Moreover, among police officers, we also verified the effects on the RDBP and triglyceride values. Several ongoing studies presented broad evidence for the positive effects of engaging in physical activity to reduce CVRF $[26,27]$. Another study on police officers in Switzerland also reported significantly lower cardiovascular risk scores and lower body fat percentages among police officers with higher CRF levels [28]. An especially significant reduction in RDBP in police officers was one notable observation because epidemiological studies demonstrated that even small blood pressure changes can have reducing effects on cardiovascular disease $[29,30]$.

On the other hand, only $5.5 \%(n=10)$ of police officers and $3.6 \%(n=8)$ of office workers achieved METs $>12$. The high rate of overweight and obese study participants may be responsible for the low number of high METs scores and the main reason for the low number of participants categorized under the "fit and not obese" group. The majority of police officers and office workers (police officers $n=33$; office workers $n=25$ ) were obese. High obesity rates in police officers have been reported in different countries by several studies [31,32]. Ramey et al. [33], moreover, demonstrated that police officers have higher obesity rates than the general public.

Research further suggests that a person's focus on physical activity wanes over the course of his or her working life. In a Norwegian progress study, Lagestad et al. [34] examined police officers' physical activity levels shortly before the end of their training period and after three years in police service. The authors showed that the frequency of physical activity and the importance of physical training decreased significantly over the course of the study. This study's results are worrying, as the physical demands of police officers on duty are high [35].

Often, there are no fixed specifications for physical activity for police officers, so maintaining such activity is primarily contingent upon the intrinsic motivation of each individual. However, good CRF is necessary to perform well during emergency situations on patrol and to improve one's own cardiovascular mortality risk. Corresponding studies by Lagestad et al. [34] and Bissett et al. [36] showed a positive attitude toward regular physical fitness check-ups. According to this study, police officers recognized the need for ongoing high fitness levels as an important criterion of their professional practice.

Apart from our results, the importance of physical activity for police officers has been underscored by the results of several studies. Steinhardt et al. [37] demonstrated that absenteeism among physically active police officers is lower than that among those who 
are seated, and Schilling et al. [38] emphasized the importance of high levels of CRF for the prevention of metabolic syndrome among police officers. This is an important factor, as the presence of a metabolic syndrome has been reported in up to $30 \%$ of police officers $[39,40]$.

Regardless of this, it has long been known that physical inactivity is a changeable risk factor for cardiovascular diseases and many other chronic diseases, such as diabetes mellitus, obesity, high blood pressure, and various tumor diseases [41]. An unhealthy lifestyle and high health hazards were already reported among office workers [42,43], who seem to be at particularly risk for developing CVRF. Sedentary behavior thus seems to be an important factor for cardiovascular risk development in office workers [44,45]. For office workers, sedentism accounts for up to $81 \%$ of all work hours and is not generally compensated by physical activity during leisure time [46]. Katzmarzyk et al. [47] further reported a dose-effect relationship between sitting time and both mortality and the presence of cardiovascular risk.

In general, previous studies described a steady and pronounced decline in mean cardiorespiratory fitness in the general population over the past few years [48]. Previous studies described low CRF among various groups of office workers [8,10]. The importance of CRF for office workers was also shown in a study by Drake et al. [49], which presented significantly lower frequencies and durations of absence due to sickness among office workers with higher CRF.

The practical implications of our study are clear: Risk reduction in all professional groups is absolutely necessary. One possibility to reduce cardiovascular risk is to train CRF. We were able to achieve lower CVRF in those with higher CRF levels. In detail, every increase in CRF was associated with a significant decrease in important cardiovascular risk factors, especially a decrease in 10-year cardiovascular risk among office workers and police officers.

Physical activity programs are important implements to achieve positive effects for cardiovascular risk reduction. One approach is moderate-intensity physical activity, which was shown to yield significant clinical improvements in CRF among office workers [50]. Most notably, reductions in body weight, BMI, and fasting glucose levels were observed [51].

\section{Strengths and Limitations}

This study features some limitations that may impact the relevance of the results. This study was conducted with a small number of participants, and the examined groups of police officers and office workers presented only a small cohort of these two occupations. Therefore, extensive prospective studies with larger sample sizes are necessary to support or refute the results. Another limitation of this study is its lack of a description for workassociated physical activity in contrast to leisure-time physical activity.

However, the strengths of this study supersede its limitations. The most important strength is our observation that a significant reduction in cardiovascular risk can be accomplished if individual CRF is high, which can be achieved independent of the profession (e.g., police officers and office workers).

\section{Conclusions}

Both the police officers and office workers had a high rate of obesity and reduced CRF according to the assessment based on METs. This obesity led to increased cardiovascular risk. The study results mainly highlighted the beneficial effects of cardiorespiratory fitness in reducing cardiovascular risk and risk factors in both groups.

Improved CRF is needed for police officers and office workers because these professions entail sedentary work. The study results indicate that it would be of great importance to encourage movement among police officers and office workers to increase CRF for the purpose of reducing and preventing cardiovascular risk in those professions. One possible solution could be to establish worksite health-promoting initiatives, such as offering nutritional courses and exercise-promoting programs. 
Author Contributions: Study conception and design: M.S., P.F. and R.L.; data acquisition: M.S., P.F. and R.L.; data analysis and interpretation: M.S., P.F., A.B., U.J. and R.L.; statistical analysis: M.S., U.J., R.V. and R.L.; drafting the manuscript: M.S., A.B. and R.L.; critical revision of the manuscript for important intellectual content: M.S., P.F., U.J., A.B., R.V. and R.L.; final approval of the version to be published: M.S., P.F., U.J., A.B., R.V., H.L. and R.L.; obtained funding: H.L. and R.L.; administrative, technical, or material support: M.S., P.F., H.L. and R.L. All authors have read and agreed to the published version of the manuscript.

Funding: We acknowledge support from the Open Access Publication Fund of the University of Muenster.

Institutional Review Board Statement: Scientific evaluation of this research received a positive assessment by the Central Ethics Commission of the University of Witten/Herdecke.

Informed Consent Statement: All participants signed their written informed consent.

Data Availability Statement: The datasets analyzed during the current study are available from the corresponding author upon reasonable request.

Acknowledgments: We thank Hiltrud Niggemann for statistical support.

Conflicts of Interest: The authors declare that they have no conflicts of interest.

$\begin{array}{ll}\text { Abbreviations } & \\ \text { Abs.VO2max } & \text { Absolute maximal oxygen uptake } \\ \text { BMI } & \text { Body mass index } \\ \text { CRF } & \text { Cardiorespiratory fitness } \\ \text { CVRF } & \text { Cardiovascular risk factors } \\ \text { HDL-cholesterol } & \text { High-density lipoprotein cholesterol } \\ \text { HR } & \text { Heart rate } \\ \text { LDL-cholesterol } & \text { Low-density lipoprotein cholesterol } \\ \text { MET } & \text { Metabolic equivalent } \\ \text { OW } & \text { Office worker } \\ \text { PO } & \text { Police officer } \\ \text { RDBP } & \text { Diastolic resting blood pressure } \\ \text { Rel. VO2max } & \text { Relative maximal oxygen uptake } \\ \text { RSBP } & \text { Systolic resting blood pressure }\end{array}$

\section{References}

1. Danaei, G.; Ding, E.L.; Mozaffarian, D.; Taylor, B.; Rehm, J.; Murray, C.J.L.; Ezzati, M. The Preventable Causes of Death in the United States: Comparative Risk Assessment of Dietary, Lifestyle, and Metabolic Risk Factors. PLoS Med. 2009, 6, e1000058. [CrossRef] [PubMed]

2. Haskell, W.; Lee, I.; Pate, R.; Powell, K.; Blair, S.; Franklin, B.; Macera, C.A.; Heath, G.W.; Thompson, P.D.; Bauman, A. Physical Activity and Public Health: Updated Recommendation for Adults from the American College of Sports Medicine and the American Heart Association. Med. Sci. Sports Exerc. 2007, 39, 1423-1434. [CrossRef] [PubMed]

3. Morris, J.N.; Heady, J.A. Mortality in Relation to the Physical Activity of Work: A Preliminary Note on Experience in Middle Age. Br. J. Ind. Med. 1953, 10, 245-254. [CrossRef] [PubMed]

4. Coenen, P.; A Huysmans, M.; Holtermann, A.; Krause, N.; Van Mechelen, W.; Straker, L.M.; Van Der Beek, A.J. Do Highly Physically Active Workers Die Early? A Systematic Review with Meta-Analysis of Data from 193696 Participants. Br. J. Sports Med. 2018, 52, 1320-1326. [CrossRef]

5. Leischik, R.; Dworrak, B.; Strauss, M.; Przybylek, B.; Dworrak, T.; Schöne, D.; Horlitz, M.; Mügge, A. Plasticity of Health. Ger. J. Med. 2016, 1, 1-17.

6. Jakobsson, J.; Malm, C.; Furberg, M.; Ekelund, U.; Svensson, M. Physical Activity During the Coronavirus (COVID-19) Pandemic: Prevention of a Decline in Metabolic and Immunological Functions. Front. Sports Act. Living 2020, 2, 57. [CrossRef]

7. Maugeri, G.; Castrogiovanni, P.; Battaglia, G.; Pippi, R.; D’Agata, V.; Palma, A.; Di Rosa, M.; Musumeci, G. The Impact of Physical Activity on Psychological Health During Covid-19 Pandemic in Italy. Heliyon 2020, 6, e04315. [CrossRef]

8. Strauss, M.; Foshag, P.; Leischik, R. Prospective Evaluation of Cardiovascular, Cardiorespiratory, and Metabolic Risk of German Office Workers in Comparison to International Data. Int. J. Environ. Res. Public Health 2020, 17, 1590. [CrossRef] 
9. $\quad$ van Uffelen, J.G.Z.; Wong, J.; Chau, J.Y.; van der Ploeg, H.P.; Riphagen, I.; Gilson, N.D.; Burton, N.W.; Healy, G.N.; Thorp, A.A.; Clark, B.K.; et al. Occupational Sitting and Health Risks: A Systematic Review. Am. J. Prev. Med. 2010, 39, 379-388. [CrossRef] [PubMed]

10. Konradi, A.O.; Rotar, O.P.; Korostovtseva, L.S.; Ivanenko, V.V.; Solntcev, V.N.; Anokhin, S.B.; Bart, V.A.; Shlyakhto, E.V. Prevalence of Metabolic Syndrome Components in a Population of Bank Employees from St. Petersburg, Russia. Metab. Syndr. Relat. Disord. 2011, 9, 337-343. [CrossRef]

11. Zimmerman, F.H. Cardiovascular Disease and Risk Factors in Law Enforcement Personnel: A Comprehensive Review. Cardiol. Rev. 2012, 20, 159-166. [CrossRef] [PubMed]

12. Magnavita, N.; Capitanelli, I.; Garbarino, S.; Pira, E. Work-Related Stress as a Cardiovascular Risk Factor in Police Officers: A Systematic Review of Evidence. Int. Arch. Occup. Environ. Health 2018, 91, 377-389. [CrossRef]

13. Marins, E.F.; David, G.B.; Del Vecchio, F.B. Characterization of the Physical Fitness of Police Officers: A Systematic Review. J. Strength Cond. Res. 2019, 33, 2860-2874. [CrossRef] [PubMed]

14. Marins, E.F.; Del Vecchio, F. Health's Patrol Program: Health Indicators from Federal Highway Policemen. Sci. Med. 2017, 27, ID25855. [CrossRef]

15. Ma, C.C.; Andrew, M.E.; Fekedulegn, D.; Gu, J.K.; Hartley, T.A.; Charles, L.E.; Violanti, J.M.; Burchfiel, C.M. Shift Work and Occupational Stress in Police Officers. Saf. Health Work 2015, 6, 25-29. [CrossRef]

16. Strauss, M.; Dahmen, J.; Hutter, S.; Brade, M.; Leischik, R. Rescue Operations Lead to Increased Cardiovascular Stress in HEMS Crew Members: A Prospective Pilot Study of a German HEMS Cohort. J. Clin. Med. 2021, 10, 1602. [CrossRef]

17. Izawa, S.; Tsutsumi, A.; Ogawa, N. Effort-Reward Imbalance, Cortisol Secretion, and Inflammatory Activity in Police Officers with 24-h Work Shifts. Int. Arch. Occup. Environ. Health 2016, 89, 1147-1154. [CrossRef] [PubMed]

18. Ramey, S.L.; Perkhounkova, Y.; Moon, M.; Tseng, H.-C.; Wilson, A.; Hein, M.; Hood, K.; Franke, W.D. Physical Activity in Police Beyond Self-Report. J. Occup. Environ. Med. 2014, 56, 338-343. [CrossRef]

19. Leischik, R.; Foshag, P.; Strauss, M.; Littwitz, H.; Garg, P.; Dworrak, B.; Horlitz, M. Aerobic Capacity, Physical Activity and Metabolic Risk Factors in Firefighters Compared with Police Officers and Sedentary Clerks. PLoS ONE 2015, 10, e0133113.

20. Sedentary Behaviour Research Network. Letter to the Editor: Standardized use of the Terms "Sedentary" and "Sedentary Behaviours". Appl. Physiol. Nutr. Metab. 2012, 37, 540-542. [CrossRef]

21. Anderson, K.M.; Odell, P.M.; Wilson, P.W.; Kannel, W.B. Cardiovascular Disease Risk Profiles. Am. Heart J. 1991, 121, $293-298$. [CrossRef]

22. Study, F.H. Ten Years Cardiovascular Disease Risk. Available online: https://www.framinghamheartstudy.org/risk-functions/ cardiovascular-disease /10-year-risk.php (accessed on 15 August 2020).

23. Wasserman, K.; Hansen, J.E.; Sue, D.Y.; Stringer, W.W.; Whipp, B.J. Principles of Exercise Testing and Interpretation: Including Pathophysiology and Clinical Applications. Med. Sci. Sports Exerc. 2005, 37, 1249.

24. Balke, B. The Effect of Physical Exercise on the Metabolic Potential, a Crucial Measure of Physical Fitness. Exerc. Fit. 1960, 73-81.

25. Strauß, M.; Foshag, P.; Przybylek, B.; Horlitz, M.; Lucia, A.; Sanchis-Gomar, F.; Leischik, R. Occupation and Metabolic Syndrome: Is There Correlation? A Cross Sectional Study in Different Work Activity Occupations of German Firefighters and Office Workers. Diabetol. Metab. Syndr. 2016, 8, 1-8. [CrossRef] [PubMed]

26. Cooper, A.J.; Brage, S.; Ekelund, U.; Wareham, N.J.; Griffin, S.J.; Simmons, R.K. Association Between Objectively Assessed Sedentary Time and Physical Activity with Metabolic Risk Factors Among People with Recently Diagnosed Type 2 Diabetes. Diabetologia 2014, 57, 73-82. [CrossRef]

27. Guidelines Subcommittee. 1999 World Health Organization-International Society of Hypertension Guidelines for the Management of Hypertension. Guidelines Subcommittee. J. Hypertens. 1999, 17, 151-183.

28. Schilling, R.; Colledge, F.; Ludyga, S.; Pühse, U.; Brand, S.; Gerber, M. Does Cardiorespiratory Fitness Moderate the Association between Occupational Stress, Cardiovascular Risk, and Mental Health in Police Officers? Int. J. Environ. Res. Public Health 2019, 16, 2349. [CrossRef] [PubMed]

29. Lin, J.S.; O'Connor, E.; Whitlock, E.P.; Beil, T.L. Behavioral Counseling to Promote Physical Activity and a Healthful Diet to Prevent Cardiovascular Disease in Adults: A Systematic Review for the U.S. Preventive Services Task Force. Ann. Intern. Med. 2010, 153, 736-750. [CrossRef]

30. MacMahon, S.; Peto, R.; Collins, R.; Godwin, J.; Cutler, J.; Sorlie, P.; Abbott, R.; Neaton, J.; Dyer, A.; Stamler, J. Blood Pressure, Stroke, and Coronary Heart Disease. Part 1, Prolonged Differences in Blood Pressure: Prospective Observational Studies Corrected for the Regression Dilution Bias. Lancet 1990, 335, 765-774. [CrossRef]

31. Heinrich, K.M.; Gurevich, K.G.; Arkhangelskaia, A.N.; Karazhelyaskov, O.P.; Poston, W.S.C. Despite Low Obesity Rates, Body Mass Index Under-Estimated Obesity among Russian Police Officers When Compared to Body Fat Percentage. Int. J. Environ. Res. Public Health 2020, 17, 1937. [CrossRef] [PubMed]

32. Alasagheirin, M.H.; Clark, M.K.; Ramey, S.L.; Grueskin, E.F. Body Mass Index Misclassification of Obesity Among Community Police Officers. Off. J. Am. Assoc. Occup. Health Nurses 2011, 59, 469-475.

33. Ramey, S.L.; Downing, N.R.; Knoblauch, A. Developing Strategic Interventions to Reduce Cardiovascular Disease Risk Among Law Enforcement Officers: The Art and Science of Data Triangulation. Off. J. Am. Assoc. Occup. Health Nurses 2008, 56, 54-62. [CrossRef] [PubMed] 
34. Lagestad, P.; van den Tillaar, R. Longitudinal Changes in the Physical Activity Patterns of Police Officers. Int. J. Police Sci. Manag. 2014, 16, 76-86. [CrossRef]

35. Bundespolizei PDd. Informationsblatt des Polizeiärztlichen Dienstes der Bundespolizei für Bewerberinnen/Bewerber über die Polizeiärztliche Untersuchung: Bundespolizeiakademie. 2019. Available online: https://www.bundespolizei.de/Web/DE/06 Karriere/05Stellenausschreibungen/_Vordrucke/infoblatt-polizeidiensttauglichkeit_file.pdf?_blob=publicationFile\&v=2 (accessed on 24 June 2019).

36. Bissett, D.; Bissett, J.; Snell, C. Physical Agility Tests and Fitness Standards: Perceptions of Law Enforcement Officers. Police Pract. Res. 2012, 13, 208-223. [CrossRef]

37. Steinhardt, M.; Greenhow, L.; Stewart, J. The Relationship of Physical Activity and Cardiovascular Fitness to Absenteeism and Medical Care Claims Among Law Enforcement Officers. Am. J. Health Promot. 1991, 5, 455-460. [CrossRef]

38. Schilling, R.; Colledge, F.; Pühse, U.; Gerber, M. Stress-Buffering Effects of Physical Activity and Cardiorespiratory Fitness on Metabolic Syndrome: A Prospective Study in Police Officers. PLoS ONE 2020, 15, e0236526. [CrossRef]

39. Rostami, H.; Tavakoli, H.R.; Rahimi, M.H.; Mohammadi, M. Metabolic Syndrome Prevalence among Armed Forces Personnel (Military Personnel and Police Officers): A Systematic Review and Meta-Analysis. Mil Med. 2019, 184, e417-e525. [CrossRef]

40. Strauss, M.; Foshag, P.; Brzek, A.; Vollenberg, R.; Jehn, U.; Leischik, R. Metabolic Syndrome in Female Police Officers and Female Office Workers: A Cross-Sectional Study in Occupations with Different Physical Activities. Diabetes Metab. Syndr. Obes. 2020, 13, 3487-3495. [CrossRef]

41. Warburton, D.E.; Nicol, C.W.; Bredin, S.S. Health Benefits of Physical Activity: The Evidence. CMAJ 2006, 174, 801-809. [CrossRef] [PubMed]

42. Lohsoonthorn, V.; Lertmaharit, S.; Williams, M.A. Prevalence of Metabolic Syndrome Among Professional and Office Workers in Bangkok, Thailand. J. Med Assoc. Thail. Chotmaihet Thangphaet 2007, 90, 1908.

43. Kennedy, R.A.; Boreham, C.A.; Murphy, M.H.; Young, I.S.; Mutrie, N. Evaluating the Effects of a Low Volume Stairclimbing Programme on Measures of Health-Related Fitness in Sedentary Office Workers. J. Sports Sci. Med. 2007, 6, 448-454.

44. Healy, G.N.; Matthews, C.E.; Dunstan, D.W.; Winkler, E.A.; Owen, N. Sedentary Time and Cardio-Metabolic Biomarkers in US Adults: NHANES 2003-2006. Eur. Heart J. 2011, 32, 590-597. [CrossRef]

45. Ford, E.S.; Caspersen, C.J. Sedentary Behaviour and Cardiovascular Disease: A Review Of Prospective Studies. Int. J. Epidemiol. 2012, 41, 1338-1353. [CrossRef]

46. Parry, S.; Straker, L. The Contribution of Office Work to Sedentary Behaviour Associated Risk. BMC Public Health 2013, 13, 296. [CrossRef] [PubMed]

47. Katzmarzyk, P.T.; Church, T.S.; Craig, C.L.; Bouchard, C. Sitting Time and Mortality from all Causes, Cardiovascular Disease, and Cancer. Med. Sci. Sports Exerc. 2009, 41, 998-1005. [CrossRef]

48. Ekblom-Bak, E.; Ekblom, Ö.; Andersson, G.; Wallin, P.; Söderling, J.; Hemmingsson, E.; Ekblom, B. Decline in Cardiorespiratory Fitness in the Swedish Working Force Between 1995 and 2017. Scand. J. Med. Sci. Sports 2019, 29, 232-239. [CrossRef] [PubMed]

49. Drake, E.; Ekblom, M.M.; Ekblom, Ö.; Kallings, L.V.; Blom, V. Cardiorespiratory Fitness and Device-Measured Sedentary Behaviour are Associated with Sickness Absence in Office Workers. Int. J. Environ. Res. Public Health 2020, 17, 628. [CrossRef] [PubMed]

50. Dalager, T.; Justesen, J.B.; Murray, M.; Boyle, E.; Sjøgaard, G. Implementing Intelligent Physical Exercise Training at the Workplace: Health Effects Among Office Workers-A Randomized Controlled Trial. Eur. J. Appl. Physiol. 2016, 116, 1433-1442. [CrossRef]

51. Maruyama, C.; Kimura, M.; Okumura, H.; Hayashi, K.; Arao, T. Effect of a Worksite-Based Intervention Program on Metabolic Parameters in Middle-Aged Male White-Collar Workers: A Randomized Controlled Trial. Prev. Med. 2010, 51, 11-17. [CrossRef] [PubMed] 